\title{
CONTUSÃO AFETA A MASSA MUSCULAR?
}

\section{Bianca Vedoin Copês Rambo ${ }^{1}$; Jefferson Potiguara de Moraes²; Camila Franco ${ }^{3}$; Bruno Stefanello Vizzotto ${ }^{4}$; Rodrigo Pereira Martins ${ }^{5}$; Rithiele Gonçalves ${ }^{5}$; Luis Ulisses Signori ${ }^{5}$; Virginia Cielo Rech ${ }^{6}$.}

\section{RESUMO}

As causas mais comuns de lesão muscular são os traumas diretos como a contusão. $\mathrm{Na}$ fase de reparo ocorre a síntese de proteínas como o colágeno. O objetivo desta pesquisa é avaliar os níveis de proteínas no músculo gastrocnêmio de ratos submetidos a lesão muscular e tratados com fonoforese e massoterapia utilizando um gel contendo carreador lipídico nanoestruturado com quercetina (CLN-Q). Os grupos foram divididos em: G1 - controle; G2 - lesão sem tratamento; G3 - lesão, tratado com ultrassom; G4 - lesão, tratado com gel CLN-Q; G5 - lesão, tratado com gel CLN-Q e ultrassom; G6 - lesão, tratado com gel CLN-Q e massoterapia; G7 lesão, tratado com massoterapia. As proteínas foram medidas no homogeneizado na diluição 1:10 (m:v) utilizando o método de Lowry et al. (1951). Foram observadas pequenas diferenças entre os grupos em relação a massa proteica. $\mathrm{O}$ aumento de proteínas pode estar associado ao processo de reparo tecidual.

Palavras-chave: Lesão muscular; Método de Lowry; Nanociências; Proteína.

Eixo Temático: Tecnologia, Inovação e Desenvolvimento Sustentável (TIDS).

\section{INTRODUÇÃO}

As lesões musculares podem ocorrer por uma variedade de mecanismos decorrentes de perturbações mecânicas, ambientais ou genéticas. As causas mais comuns são traumas mecânicos e lesões diretas como a contusão, que pode causar degradação da proteína muscular e necrose (HAUPENTHAL et al., 2020; SILVEIRA et al., 2010). Embora existam diferentes fatores que levam à lesão como atividade

\footnotetext{
${ }^{1}$ Acadêmica do Curso de Biomedicina - Universidade Franciscana. biancarambo@outlook.com

2 Programa de Pós-Graduação em Nanociências - Universidade Franciscana. jpotiguaramoraes@yahoo.com.br

${ }^{3}$ Professora no Curso de Farmácia e PPG-Nanociências - Universidade Franciscana. cf@ufn.edu.br

${ }_{4}^{4}$ Professor no Curso de Biomedicina - Universidade Franciscana. bvizzotto@ufn.edu.br

5 Universidade Federal de Santa Maria. rodrigo_martins89@hotmail.com; fisiorithiele@gmail.com;

I.signori@hotmail.com

${ }^{6}$ Professora no Curso de Biomedicina e PPG-Nanociências - Universidade Franciscana. vga.cielo@gmail.com
} 
física, contrações excêntricas extenuantes, traumas diretos e doenças sistêmicas, o processo de reparo e regeneração é semelhante na maioria dos casos (SILVEIRA et al., 2010).

As lesões musculoesqueléticas decorrentes de contusão são caracterizadas pela compressão das células musculares, devido a um forte impacto na superfície do músculo, causando danos aos elementos contráteis da estrutura muscular. Em decorrência da lesão, ocorre a destruição das fibras musculares, miofilamentos, linha $\mathrm{Z}$ e sarcômeros. As fibras lesadas sofrem um processo de necrose e a ativação das células inflamatórias induz a uma resposta inflamatória local (TOMAZONI et al., 2017). Esse processo inflamatório aumenta a produção de espécies reativas de oxigênio (EROS). Em concentrações fisiológicas, as EROS desempenham um papel na manutenção das funções celulares, mas quando produzidas em excesso, causam estresse oxidativo que gera danos aos constituintes celulares como lipídios, proteínas e DNA (HAUPENTHAL et al., 2020). O estresse oxidativo pode ocorrer em uma série de locais potenciais dentro do músculo traumatizado, sendo que as fontes primárias de radicais livres incluem as mitocôndrias, enzimas xantina oxidase, metabolismo prostanoide e NADPH oxidases (SILVEIRA et al., 2010).

O mecanismo de reparo da lesão tecidual se divide em etapas de degeneração, inflamação, regeneração e fibrose, dependendo da gravidade da lesão (URSO, 2013). Dentre os tratamentos para estimular a regeneração muscular estão a fonoforese e massoterapia. Na técnica de fonoforese realiza-se a aplicação de um ultrassom terapêutico no local da lesão, geralmente com a utilização de um gel, cuja finalidade é aumentar a absorção transdérmica de fármacos (AZAGURY et al., 2014; POLAT et al., 2011). A massoterapia consiste na manipulação física do músculo lesionado para reduzir a dor e promover a recuperação (CRANE et al., 2012).

Os flavonoides são alvos de estudos para o tratamento de diversas doenças devido a suas propriedades terapêuticas. A quercetina exerce diversos efeitos biológicos benéficos ao organismo como efeitos anti-inflamatório, antioxidante, antiinfeccioso, anticâncer, quimiopreventivo, neuroprotetor e anti-hipertensivo. Sua capacidade de eliminar radicais livres previne o estresse oxidativo. No entanto, esse composto possui uma biodisponibilidade baixa e seu metabolismo é complexo 
(CARULLO et al., 2017). Integrar a quercetina ao carreador lipídico nanoestruturado (CLN) melhora a sua biodisponibilidade e solubilidade aquosa. O CLN apresenta uma estrutura composta por lipídios sólidos e líquidos, que melhora a permeação intracelular e protege a substância contra $0 \mathrm{pH}$ fisiológico e enzimas (MONTENEGRO et al., 2016). As características do CLN o tornam promissor para tratamentos transdérmicos. Portanto, o desenvolvimento de um gel contendo carreadores lipídicos nanoestruturados com quercetina (CLN-Q) permite que ele seja associado a fonoforese e a massoterapia para potencializar a permeação cutânea da substância no tratamento da contusão muscular.

\section{METODOLOGIA}

\subsection{Experimento in vivo}

Para essa pesquisa foram utilizados 70 ratos machos distribuídos aleatoriamente em 7 grupos ( $n=10)$ : G1 - grupo controle, sem lesão e sem tratamento; G2 - grupo lesão sem tratamento; G3 - grupo lesão, tratado com ultrassom; G4 - grupo lesão, tratado com gel CLN-Q; G5 - grupo lesão, tratado com gel CLN-Q e ultrassom; G6 - grupo lesão, tratado com gel CLN-Q e massoterapia; G7 - grupo lesão, tratado com gel comum e massoterapia. Os ratos passaram por uma semana de ambientação, mantidos em uma sala com ciclo claro/escuro de 12 $\mathrm{h}$, temperatura de $22 \pm 1{ }^{\circ} \mathrm{C}$ e acesso livre à comida e água. Este experimento foi aprovado pela Comissão de Ética no Uso de Animais (CEUA/UFN), sob o número 02/2019.

O gel com CLN-Q foi produzido, caracterizado e aplicado com fonoforese e massoterapia sobre o músculo gastrocnêmio dos ratos submetidos à lesão muscular. A contusão foi realizada conforme o método de Crisco et al. (1994), utilizando um equipamento que lesiona o músculo a partir de um impacto. $O$ tratamento iniciou $24 \mathrm{~h}$ após a lesão. Foram realizadas 5 aplicações com 12 horas de intervalo entre elas. As aplicações do ultrassom foram executadas por 5 minutos com um ultrassom terapêutico de $1 \mathrm{MHz}$, intensidade de $0,5 \mathrm{~W} / \mathrm{cm}^{2}$ SPTA (do inglês spatial peak-temporal average), na forma de onda pulsada, ciclo de trabalho de $20 \%$ ( $2 \mathrm{~ms}$ de tempo on e $8 \mathrm{~ms}$ de tempo off). O tratamento com massoterapia e gel 
CLN-Q também foi realizado de $12 \mathrm{em} 12 \mathrm{~h}$, durante 5 minutos com movimentos leves deslizando no sentido longitudinal da fibra muscular. Ao final do tratamento os ratos sofreram eutanásia por anestesia intraperitoneal, com uma sobredose de cetamina de $500 \mathrm{mg} / \mathrm{kg}$ de massa corporal. Em seguida, extraiu-se o sangue, coração, rins, fígado e o músculo gastrocnêmio. Todas as amostras foram armazenadas em freezer $-80^{\circ} \mathrm{C}$ para posterior análise. $\mathrm{O}$ músculo gastrocnêmio foi homogeneizado em soro fisiológico (diluição 1:10), centrifugado a $800 \times$ g/10 min, a $4{ }^{\circ} \mathrm{C}$ e parte do sobrenadante do homogeneizado foi destinado a determinação das proteínas.

\subsection{Determinação de proteínas}

O conteúdo de proteínas do músculo gastrocnêmio foi determinado pelo método de Lowry et al. (1951) utilizando albumina sérica bovina como padrão. A unidade está em mg proteína/mL.

\subsection{Análise estatística}

Os dados foram analisados por ANOVA seguidos do teste de Dunnett, com os tratamentos comparados ao grupo controle (G1). Os dados estão representados pelas médias \pm desvio padrão (DP). O nível de significância é de $5 \%(p<0,05)$.

\section{RESULTADOS E DISCUSSÕES}

O músculo esquelético é composto por 2 componentes principais, as fibras musculares e o tecido conjuntivo. As fibras musculares apresentam nervos e são responsáveis pela função contrátil do músculo, enquanto o tecido conjuntivo fornece a estrutura que une as células musculares individuais. As miofibrilas, os capilares e os nervos são envolvidos pelo tecido conjuntivo, formando a estrutura muscular (JÄRVINEN et al., 2005), conforme a figura 1. 
Figura 1. Estrutura muscular (adaptada de Dave Carlson).

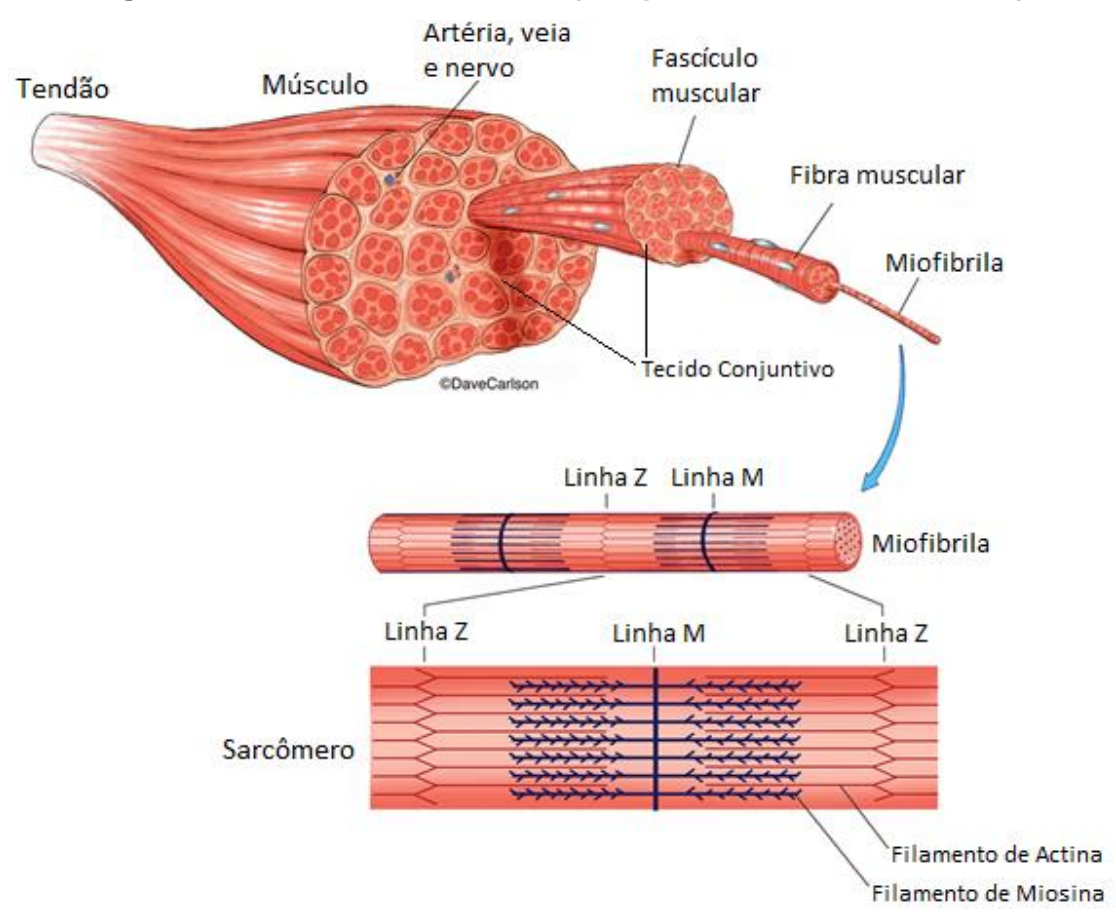

Fonte <https://www.carlsonstockart.com/photo/muscle-structure-illustration/>

Quando o músculo esquelético é lesado, as fibras musculares são rompidas e ocorre a formação de um hematoma no local. $\mathrm{O}$ dano à matriz celular e a necrose das células desencadeia um processo inflamatório, caracterizado por vasodilatação e aumento da permeabilidade vascular (HAUPENTHAL et al., 2020; URSO, 2013). A fibrina derivada do sangue e a fibronectina se reticulam para formar o tecido de granulação precoce (JÄRVINEN et al., 2005). Na fase inflamatória aguda (24 - 48 h), inicia a liberação de citocinas pró-inflamatórias no local da lesão, incluindo TNF$\alpha$, IFN-y e IL-1 $\beta$ que estimulam os macrófagos a fagocitar o tecido necrótico. Em seguida, inicia-se a fase de reparo tecidual, onde há liberação de citocinas antiinflamatórias que estimulam a proliferação e diferenciação celular por células satélites, deposição de colágeno e angiogênese (HAUPENTHAL et al., 2020; URSO, 2013). Durante a fase de reparo, as células satélites se proliferam e diferenciam em mioblastos que se fundem com as fibras musculares lesadas. Concomitante com a regeneração das fibras musculares ocorre a produção de cicatriz do tecido conjuntivo e o crescimento capilar (URSO, 2013). Os fibroblastos começam a sintetizar as proteínas e proteoglicanos da matriz extracelular para restaurar a 
integridade da estrutura do tecido conjuntivo. Dentre as proteínas sintetizadas a tenascina- $\mathrm{C}$ e a fibronectina possuem propriedades elásticas e fornecem força e elasticidade ao tecido de granulação inicial. A formação de fibronectina é seguida pela formação de colágeno tipo III e, após alguns dias, inicia-se a produção de colágeno tipo I, que condensa o tecido de granulação em uma massa de tecido conjuntivo, gerando o tecido cicatricial. Por fim, na fase de remodelação, ocorre a maturação das miofibrilas regeneradas, a reorganização do tecido cicatricial e a recuperação da capacidade funcional do músculo (JÄRVINEN et al., 2005).

Em geral, o músculo esquelético lesado se regenera rapidamente formando miotubos em 3 dias, fibras musculares funcionalmente reinervadas em 4 a 5 dias e fibras totalmente reparadas após 21 a 28 dias (SILVEIRA et al., 2010). Dentre os tratamentos utlizados, o papel do ultrassom na regeneração e reparo dos tecidos moles tem sido amplamente discutido. Em nível celular, as mudanças nas taxas de difusão e permeabilidade da membrana aos íons devido ao fluxo acústico e cavitação estável podem estimular as células pela regulação positiva das moléculas de sinalização. Com isso, a utilização do ultrassom terapêutico em conjunto a fármacos anti-inflamatórios ou antioxidantes pode potencializar os efeitos positivos no tratamento (HAUPENTHAL et al., 2020; SILVEIRA et al., 2010). A massoterapia é uma forma bem conhecida de medicina alternativa que consiste na manipulação física do músculo e do tecido conjuntivo em um local de lesão, inflexibilidade ou dor para promover a recuperação. A massagem terapêutica modera a inflamação, melhora o fluxo sanguíneo e reduz a rigidez do tecido, reduzindo a dor local (CRANE et al., 2012; WEERAPONG; HUME; KOLT, 2005).

\subsection{Resultados: Quantificação de Proteínas}

A quantidade de proteína $(\mathrm{mg} / \mathrm{mL})$ do músculo gastrocnêmio com ou sem contusão muscular estão representados na tabela 1. Os teste-t de Dunnet realizam uma comparação entre o grupo controle e os grupos com lesão. Os valores de significância dos grupos quando comparados ao grupo controle indicam que houve diferença significativa $(P<0,05)$ apenas nos grupos de lesão tratada com Gel CLN-Q e lesão tratada com massoterapia e Gel CLN-Q, cujos valores foram de 0,009 e 
0,015, respectivamente. Os resultados demonstram que não ocorreu diferença significativa entre o grupo controle (sem lesão) e o grupo lesão (sem tratamento).

Tabela 1. Quantidade de proteína do músculo gastrocnêmio com ou sem contusão muscular.

\begin{tabular}{|l|c|c|}
\hline \multicolumn{1}{|c|}{ GRUPOS } & MÉDIA $\pm \mathrm{DP}(\mathrm{mg} / \mathrm{mL})$ & $P$ \\
\hline G1 - Controle & $5,3 \pm 0,8$ & $\mathrm{~ns}$ \\
\hline G2 - Lesão & $5,7 \pm 0,8$ & $\mathrm{~ns}$ \\
\hline G3 - Lesão e UST & $5,9 \pm 0,6$ & $\mathrm{~ns}$ \\
\hline G4 - Lesão e Gel CLN-Q & $6,5 \pm 0,7$ & 0,009 * \\
\hline G5 - Lesão, UST e Gel CLN-Q & $6,2 \pm 0,7$ & $\mathrm{~ns}$ \\
\hline G6 - Lesão, massoterapia e Gel CLN-Q & $6,4 \pm 0,6$ & $0,015^{*}$ \\
\hline G7 - Lesão e massoterapia & $6,2 \pm 0,9$ & $\mathrm{~ns}$ \\
\hline
\end{tabular}

Os resultados representam médias \pm desvio padrão (DP). Os dados foram analisados por ANOVA e teste de Dunnett. As diferenças entre as médias são significativas para $\mathrm{P}<0,05$. UST: ultrassom terapêutico; CLN-Q: Carreador lipídico nanoestruturado com quercetina; ns: não significante.

\section{CONCLUSÃO}

As lesões musculares resultam de uma varidade de mecanismos que apresentam características comuns ao início da lesão muscular e aos processos de reparo e regeneração. Os resultados demonstram que não houve diferença entre o grupo lesão e o grupo controle, porém foram observadas pequenas diferenças entre os grupos em relação a massa proteica. Apesar dos tratamentos apresentarem efeitos positivos, não há indicações que eles influenciam os níveis de massa muscular. O pequeno aumento de proteínas ocorre devido ao processo de reparação e regeneração, que sintetiza proteínas como fibronectina, tenascina-C e colágeno no local da lesão. Com isso, podemos concluir que a contusão não afetou a massa muscular. 


\section{AGRADECIMENTOS}

Os autores gostariam de agradecer a Fundação de Amparo à Pesquisa do Estado do Rio Grande do Sul (FAPERGS) e a Universidade Franciscana (UFN) pelo suporte para a realização do presente trabalho.

\section{REFERÊNCIAS}

AZAGURY, A. et al. Ultrasound mediated transdermal drug delivery. Advanced Drug Delivery Reviews, v. 72, p. 127-143, jun. 2014.

CARULLO, G. et al. Quercetin and derivatives: useful tools in inflammation and pain management. Future Medicinal Chemistry, v. 9, n. 1, p. 79-93, jan. 2017.

CRANE, J. D. et al. Massage Therapy Attenuates Inflammatory Signaling After Exercise-Induced Muscle Damage. Science Translational Medicine, v. 4, n. 119, p. 119ra13-119ra13, 1 fev. 2012.

CRISCO, J. J. et al. A Muscle Contusion Injury Model: Biomechanics, Physiology, and Histology. The American Journal of Sports Medicine, v. 22, n. 5, p. 702-710, set. 1994.

HAUPENTHAL, D. P. DOS S. et al. Effects of phonophoresis with ibuprofen associated with gold nanoparticles in animal model of traumatic muscle injury. European Journal of Pharmaceutical Sciences, v. 143, p. 105120, fev. 2020.

JÄRVINEN, T. A. H. et al. Muscle Injuries: Biology and Treatment. The American Journal of Sports Medicine, v. 33, n. 5, p. 745-764, maio 2005.

LOWRY, O. H. et al. Protein measurement with the Folin phenol reagent. The Journal of Biological Chemistry, v. 193, n. 1, p. 265-275, nov. 1951.

MONTENEGRO, L. et al. From nanoemulsions to nanostructured lipid carriers: A relevant development in dermal delivery of drugs and cosmetics. Journal of Drug Delivery Science and Technology, v. 32, p. 100-112, abr. 2016.

POLAT, B. E. et al. Ultrasound-mediated transdermal drug delivery: Mechanisms, scope, and emerging trends. Journal of Controlled Release, v. 152, n. 3, p. 330348, jun. 2011.

SILVEIRA, P. C. L. et al. Effects of Therapeutic Pulsed Ultrasound and Dimethylsulfoxide (DMSO) Phonophoresis on Parameters of Oxidative Stress in Traumatized Muscle. Ultrasound in Medicine \& Biology, v. 36, n. 1, p. 44-50, jan. 2010. 
TOMAZONI, S. S. et al. Effects of photobiomodulation therapy and topical nonsteroidal anti-inflammatory drug on skeletal muscle injury induced by contusion in rats-part 1: morphological and functional aspects. Lasers in Medical Science, v. 32, n. 9, p. 2111-2120, dez. 2017.

URSO, M. L. Anti-inflammatory interventions and skeletal muscle injury: benefit or detriment? Journal of Applied Physiology, v. 115, n. 6, p. 920-928, 15 set. 2013.

WEERAPONG, P.; HUME, P. A.; KOLT, G. S. The Mechanisms of Massage and Effects on Performance, Muscle Recovery and Injury Prevention: Sports Medicine, v. 35, n. 3, p. 235-256, 2005. 